\title{
Total Reward Strategy: A Human Resources Management Strategy Going with the Trend of the Times
}

\author{
Zhou Jiang (Corresponding author) \\ Department of Management Administration, Yeungnam University \\ Office of International Programs, 214-1 Dae-dong, Gyeongsan, Gyeongbuk 712-749, South Korea \\ Tel: 82-10-8442-0420Ｅ-mail: jiangzhou51@live.cn \\ Qian Xiao \\ Department of Management Administration, Yeungnam University \\ Office of International Programs, 214-1 Dae-dong, Gyeongsan, Gyeongbuk 712-749, South Korea \\ Tel: 82-10-5895-0219 E-mail: xiaoqian219@hotmail.com \\ Henan Qi \\ Department of Management Administration, Yeungnam University \\ Office of International Programs, 214-1 Dae-dong, Gyeongsan, Gyeongbuk 712-749, South Korea \\ Tel: 82-10-3143-3538Ｅ-mail: qihenan@live.cn \\ Lei Xiao \\ College of Science, Northwest A\&F University \\ Shaanxi 712100, China \\ E-mail: xiao.lei.0918@hotmail.com
}

\begin{abstract}
As a modern reward management method, total reward strategy has been used more and more by managers and scholars. Like all the other mature human resources management approaches and strategies, total reward strategy need to be analyzed and practiced throughout the time to make it work effectively and perfectly. In this article, the dimensionalities of total reward strategy which varies at all times has been summarized through the trend of times and redefined. Managers would gain remarkable profits for the organization they governed if they use the integrated total reward strategy properly. The strategy will not only improve the performance of staffs, act important role of decision making process of an organization, but also solve existing and potential compensation problems as well.
\end{abstract}

Keywords: Total reward strategy, Human resource management, Modern management, Motivation

\section{Introduction}

Among all kinds of budgets in an organization, remuneration cost remains a part of great importance. With the speedy update of the modern world, however, the traditional remuneration management has been facing great challenges both in public and private sectors under the current economic and business circumstance, and then come a lot of problems which can affect the performance of an organization and even cause existential threats. Survey has demonstrated that the cash reward which was paid most attention to is not as important as in the past. Based on a 2002 survey of 1,500 employees (of all ages) conducted by Nelson Motivation, Inc., San Diego, California, the ranks of employee motivators in descending order are as follows: a learning activity, flexible working hours, verbal praise, increased authority, autonomy, time with their manager, time off from work, public praise, choice of assignment and written praise. What is noteworthy is that the cash reward ranks 15th in importance (Reynolds, 2005). In recent years, some other reward-related glossaries also spring up as the progress of new-fashioned market economics, for example, salary management, salary administration, payment (or pay) management, compensation management, reward management etc. However, the common ground is that all of them focus on how to redound employees, simply in slightly different approaches.

Modern Rewards Management appears and develops in the context of managing transformation; it not simply acknowledges and redounds upon what the members have contributed to the organization, in fact, it's a specific action 
scheme of company strategic objective and values outlook conversion. To some extent, Modern Rewards Management breaks through the categories of "Money" and substance, which indicates that indirect income and some no-monetary compensation have been playing parts of increasing importance in Reward Structure Design. Generally, Modern Rewards Management is carried out through Total Reward Management which matches with the work ethic and pursuit of the present employees, and it is an important reflection of emphasizing the relationship between enjoyment of reward elements and performance.

\section{Reward Systems}

\subsection{Interpretation of Reward}

Reward is the compensation which an employee receives from an organization (mainly refer to enterprises) for his or her service. It not simply contains direct currencies and other forms which can convert to currencies, but also a comfortable office, favorable interpersonal relationship inside the organization, having access to decision-making involvement, the challenge and sense of achievement, preferable growth opportunities and so forth these kinds of forms which is difficult to measure in various currencies.

From marketing communication, reward is the market form of human resources value and form the distribution point which is the return of respective contribution of human capital. Reward has compensatory function; it is an exchange of the service one employee has offered or the retribution for the done work. In addition, motivation is another function of reward, for working quality, the degree of focusing on customers and enthusiasm of learning new skills will be influenced by the decision-making of reward and the ways in which employees get their rewards. Regulatory function of reward is embodied in several aspects which include reasonably allocating labor force and modulating the configuration of quality of labor force. And it is obvious that reasonable reward system can help bring effectual income far beyond the cost.

\subsection{Development of Reward System}

The concepts concerned with reward have experienced five phases through summing up the relevant records (Refer to table.1). Here "Total Compensation" and "Total Reward" are listed separately, however, they are often counted as the different expressive forms of one management approach, even though some admit the slight difference between them.

It's obvious that nowadays the reward system will not only focus on the employee's payment but take more attractive non-financial benefits into account in the motivation management. And out of question, it is the certain uptrend that modern total reward strategy will be popular in varieties of companies and get its rigid status in this highly developing world.

\subsection{Modern Reward Management-Total Reward Strategy}

Fernandes (1998) describes total reward as "The sum of the values of each element of an employee's reward package." Total Reward begins with total remuneration, the subset of Total Rewards, which compromises all the elements of rewards that can be valued in dollar terms. And it is a plan for allocating rewards resources in a manner that directs the business to the successful execution of its objectives (Manas \& Graham, 2002).Total reward is the term that has been adopted to describe a reward strategy that brings additional components such as learning and development, together with aspects of the working environment, into the benefits package. (Armstrong \& Brown, 2001) Worldatwork, the Total Rewards Association of U.S., defines total rewards as all of the tools available to the employer that may be used to attract, motivate and retain employees. It also indicates that total rewards include everything the employee perceives to be of value resulting from the employment relationship (Worldatwork, 2006).

It goes beyond standard remuneration by embracing the company culture, and is aimed at giving all employees a voice in the operation, with the employer in return receiving an engaged employee performance. In other words, total reward provides a broader view to treat everything what an enterprise can offer to its staff and everything what the employees can promise to their companies, which embodies the fundamental change of management thinking model of company high-level superintendents.

In recent years, total reward has been becoming a more and more popular facet which has caught many scholars' attention. As a part of human resources management practice, total reward has also been introduced into varieties of enterprises to improve their competitiveness so that they will have the abilities to survive in the global marketing warfare.

Now, total reward is an advanced model of human resources management which microscopically accelerates enterprise development and macroscopically boosts the advancement of social economic environment. Compared with traditional rewards system, total reward much more deeply reflects in what ways enterprises can attract, motivate and retain talents, in what ways employee performances which accord with corporate goal will appear and in what ways the excellent employees should be motivated and praised. 


\section{Theory Basis of Total Reward Strategy}

Maslow's need hierarchy theory (1943), supposed to be a motivation basis has been used to interpret the entire spectrum of human behavior. Maslow proposed that motivation is a function of five basic needs-physiological, safety, love, esteem and self-actualization-which are arranged in the predictable stair-step fashion (refer to Figure 1), and he explained that a person's physiological needs must be firstly met followed by safety needs, and so on up the need hierarchy (Kreitner \& Kinicki, 2007). When designing total reward strategy, employees' multifarious needs must be well considered, Maslow's points will help the organization reach its expectation.

Alderfer's ERG theory assumes that people have three types of needs: existence, relatedness and growth, and it is partly based on some of Maslow's thinking. These three categories are also arranged orderly, being from existence needs to relatedness needs and then to growth needs from lowest-level to highest-level. Unlike Maslow' ideas, ERG theory demonstrates that a higher-level need can be a motivator even if a lower-level need is not fully satisfied, and needs at more than one level can be motivators at any time (George \& Jones, 2002). Total reward strategy also follows Alderfer's thought, and the different components might be used in the mean time, which depends on the organizations' goals and strategies.

The two-factor theory put forward by (1966) divides job-related factors into hygiene factors and motivators. Hygiene factors are those led by work but not involve work itself while motivators are those carry out relevant work-related behaviors, and motivation will not be significant unless both of the two kinds of factors are present. For instance, sometimes several elements of total reward strategy must be synchronously provided by organizations to meet the employees' needs so as to produce motivation bringing back more behalf.

Focused on the ways in which workers decide which specific behaviors to perform and how much effort to exert, Expectancy Theory predicts one's level of motivation depends on the attractiveness of the rewards sought and the probability of obtaining those rewards (Vroom, 1994; Bohlander \& Snell, 2004). If employees perceive that they may get valued rewards from the organization, they tend to put greater effort into work. Expectancy Theory includes three dimensions, say, expectancy, instrumentality and valence, the level of all of which must be high if desired behaviors are looked forward to in employees' work. The position of Expectancy Theory in total reward strategy can be inferred from Figure 2 (Bohlander \& Snell, 2004) showing the relationship between pay-for-performance and the expectancy theory of motivation.

It's certain that the staff want their needs satisfied, however, they also would like to be treated fairly by the organization. Adams' Equity Theory concentrates on the concept of fairness in the workplace. Employees are probable to compare the inputs they devote to the work with the outputs they receive from the organization. The equity theory of motivation assumes a balance of employee inputs and outputs as compared to others are illustrated in the form of picture in Figure 3 (Drafke \& Kossen, 2002). Once they feel they get less outputs than inputs, which means there isn't a balance, employees are tend to be unsatisfied and not motivated. Thus, when total reward strategy is brought to bear it must assure the employees realize the justice of the corporation, for example the procedural justice of performance management.

\section{Dimensionalities of Total Reward Strategy}

As a burgeoning reward-package pattern, researchers have given various subsets of total reward strategy, although in general this modern management methodology can be divided into material and immaterial components.

Francis and Fernandes (1998) outlined the principal elements of total reward which include basic salary, variable pay, pension benefits, death-in-service benefits, long-term disability benefits, private medical insurance, vacation entitlement, company car schemes, share schemes, mortgage subsidies etc. Patricia and Jay (2000a) made an analysis of total reward components which refer to individual growth, compelling future, total pay and positive workplaces. They hold that people work for more than just pay, they are also looking for an organization which has a powerful vision of where it is going and how it plans to get there, and they want to get individual growth in acquiring skills that prepare them to add value to the business. Thus, combinations of base pay, variable pay, recognition and celebration and benefits are essential to providing a complete total reward package (Patricia \& Jay, 2000b) Lyons and Ben-Ora (2002) indicate that total reward strategy is the best foundation of pay for performance. They define total reward strategy to include following: base salary, variable pay (containing short-term incentives and long-term incentives), other compensation, perquisites, benefits and performance management. Moreover, a total strategy may also include training, career development, coaching and other employee-related policies.

Tropman (2001) suggested that the concept of total compensation which he considered as "new new pay" be expressed in terms of an equation with ten variables. $\mathrm{TC}=(\mathrm{BP}+\mathrm{AP}+\mathrm{IP})+(\mathrm{WP}+\mathrm{PP})+(\mathrm{OA}+\mathrm{OG})+(\mathrm{PI}+\mathrm{QL})+\mathrm{X}$, where $\mathrm{TC}$ $=$ total compensation; $\mathrm{BP}=$ base pay, or salary; $\mathrm{AP}=$ augmented pay, that is, any one-time payment, even if received at regular intervals; IP = indirect pay; $\mathrm{WP}=$ works-pay, that is, employer-subsidized equipment, uniforms, and so on; $\mathrm{PP}=$ perks-pay, that is, special benefits - anything from accessories to employee discounts on company products; OA = 
opportunity for advancement and increased responsibility; $\mathrm{OG}=$ opportunity for growth, both through on-the-job training and through off-site training and degree attainment; PI = psychic income, the emotional enhancements provided by the job itself and the setting; $\mathrm{QL}=$ quality of life, that is, opportunity to express other important aspects of life; $\mathrm{X}=$ any unique element that an employee wants that the workplace can facilitate.

In addition, in 2001, the Total Rewards Association introduced a relatively new framework of total rewards in order to explain the concept of total rewards more clearly. There are three elements in this framework: compensation, benefits and work experience (including recognition, work/life balance, company culture, employee development and environment are involved in this element.) However, Worldatwork afterwards thought that "the work experience" aspect of the model put forward in 2001 included aspects of employment that might be some components of the overall working experience. In 2005, the Worldatwork Public Policy Staff excogitated another more specific outline of total reward which contained four elements: pay (base salary, variable pay, recognition and stock are included), benefits (health care, retirement, savings and time off are included), learning \&development (career development, performance management, succession planning and training are included), work environment (organization climate, leadership, performance support and work/life balance are included).

As what has been mentioned, nowadays people do not work simply for pay, they also want get chances for individual development through which they're able to obtain new knowledge and apply their own talent and valuable skills. As well, the compelling future and positive workplace may be other facets employees are pursuing. Based on this temporized trend, Patricia and Jay (2003) constructed a four-component module of Total Reward which is shown in table 2.

Another sample total reward strategy framework, which was built by JLARC/Commonwealth of Virginia in 2008, contains three main segments that are compensation, benefits (health) and work/life environment. Specifically, compensation provides competitive base salary levels necessary to attract and retain talent and compensates for day-to-day responsibilities performed at fully acceptable level and above; Benefits provides flexible and market competitive health benefits to support employment brand and support attraction and retention; And work/life environment provides elastic work practices, telecommuting and support to promote the appropriate balance of productivity and employee engagement. Furthermore, Commonwealth also suggested options to consider, for example, base pay, total cash compensation, benefits, retirement and work/life etc.

\section{Management Role of Total Reward Strategy}

The performances of the staff in an organization adopting total reward strategy become of more statistical generalization, which attracts an increasing number of companies. Introducing total reward strategy probably improves not only employees' work efficiencies, job satisfaction and job performances but their psychological contract and organizational citizenship behaviors. Because of this effective management method, organizations have more channels to acquaint with employees' work life and other needs; in other way round, the personnel can keep positive attitude towards the organizations, might being less stressful or fairly treated or some else.

Ittner and Larcker (1995) found that among less extensive users of formal quality improvement practices, greater reliance on nontraditional information and reward systems is associated with higher performance. Organizations that focus on developing an integrated rewards program that helps to improve accountability, flexibility, attraction, and retention excellence; is well communicated; and provides technology tools can add significant shareholder value. What's more, the development of a total rewards program in support of the global rewards philosophy warrants a strategic approach (White, 2005). Total Reward is also an important aspect to be considered when some decision processes happen in an organization.

As Total Reward is put forward on the basis of total compensation which has been using in a large number of companies these years, therefore the researches on total compensation and some other reward theories also provide the development of total reward with potent backgrounds. Total compensation could have an effect on attendance if, as in efficiency wage theories, directors who are paid more attend more meetings because they care more about keeping their jobs (Adams \& Ferreira, 2008). The relationship between total compensation (not including meeting fees) and attendance problems is negative, but not always statistically significant (Jensen \& Murphy, 1990; Adams \& Ferreira, 2008). Elements of recognition and reward can be as important as structure in achieving the desired synergism that accompanies cross-functional cooperation (Appeldorn, 2008).

\section{Some Conclusions}

Total reward strategy is a holistic approach aligning with business strategy and people strategy; it encompasses everything employees value in their employment relationship like compensation, benefits, development and the work environment (Kaplan, 2007). This newly coming management approach acts according to the circumstance, helps with costing savings, brings about maximum return on the rewards strategy adoption, and builds up employment brand, all of which are likely to contribute to both short-term and long-term goals of an organization. As a reward strategy of 
effectiveness, it's able to gain enough good information of employees and conduct objective analysis, so that the organization can make wise decisions and assess their influences internal and external. In spite of diverse definitions, structures and functions mentioned by academicians and administrators, there still is a trend that Total reward strategy will move along because of the standards which have not been unified and have been improving and perfecting.

\section{References}

Adams, R. B. \& Ferreira, D. (2008). Do directors perform for pay? Journal of Accounting and Economics, Vol.46, pp. $154-171$.

Appeldorn, R. H. (2008). Technology Transfer in a Diversified, Global Manufacturing Company. Journal of Technology Transfer, Vol. 22 (3): 57-64.

Armstrong, M. \& Brown, D. (2001). New Dimensions in Pay Management, Chartered Institute of Personnel and Development.

Bohlander, G. \& Snell, S. (2004). Managing human resources, 13th Edition.

Drafke, M. W. \& Kossen, S. (2002). The human side of organizations, 8th Edition, pp. 287.

Fernandes, F. N. (1998). Total Reward-An Actuarial Perspective. Actuarial Research Paper, No.116.

George, J. M. \& Jones, G. R. (2002). Organizational Behavior, 3rd Edition, pp. 191.

Herzberg, F. (1966). Work and the nature of man. Cleveland: World.

Ittner, C. D. \& Larcker, D. F. (1995). Total Quality Management and the Choice of Information and Reward Systems. Journal of Accounting Research, Vol. 33, Studies on Managerial Accounting, pp. 1-34.

Jensen, M.C. \& Murphy, K.J., (1990). Performance pay and top-management incentives. Journal of Political Economy, Vol.98, pp. 225-264.

JLARC/Commonwealth of Virginia. (2008). Total Rewards Assessment Observations and Suggested Alternetives.

Kaplan, S. L. (2007). Business Strategy, People Strategy and Total Rewards. Benefits \& Compensation Digest, Vol. 44, No. 9, pp. 12-19.

Kreitner, R. \& Kinicki, A. (2007). Organizational Behavior, 17th Edition, pp. 237.

Lyons, F. H. \& Ben-Ora, D. (2002) Total Rewards Strategy: The Best Foundation of Pay for Performance. Compensation \& Benefits Review, Vol. 34, No. 2, pp. 34-40.

Manas, T. M., \& Graham, M. D. (2002). Creating a total rewards strategy: a toolkit for designing business-based plans. Publisher: AMACOM Div American Mgmt Assn.

Maslow, A. H. (1943). A theory of human motivation. Psychological Review, pp. 310-396.

Patricia, K. Z. \& Jay, R. S. (2003). Bring Practical Total Rewards to Your Organization. PIHRAScope, Vol. XLXVII, No. 11, pp. 8-9, 20-21.

Patricia, K. Z., \& Jay R. S. (2000b). Total Rewards for New and Old Economy Companies. Compensation \& Benefits Review, Vol. 32, No. 6, pp. 20-23.

Patricia, K. Z., \& Jay, R. S. (2000a). Pay People Right! Breakthrough Reward Strategies to Create Great Companies, San Francisco: Jossey-Bass Publishers.

Reynolds, L. A. (2005). Communicating Total Rewards to the Generations. Benefits Quarterly, Second Quarter.

Tropman, J. E. (2001) The compensation solution: how to develop an employee-driven rewards system. University of Michigan Business School and management series. Publisher: John Wiley and Sons.

White, R. (2005). A Strategic Approach to Building a Consistent Global Rewards Program. Compensation \& Benefits Review, Vol. 37, No. 4, pp. 23-40.

Vroom, V. H. (1994). Work and motivation (San Francisco: Jossey-Bass). 
Table 1. The five phases of reward

\begin{tabular}{|c|c|}
\hline The Modalities of Reward & Specific Descriptions \\
\hline Wage & $\begin{array}{c}\text { A wage is usually a financial compensation, received by a worker } \\
\text { in exchange for their labor. }\end{array}$ \\
\hline Salary & $\begin{array}{l}\text { A salary is a form of periodic payment from an employer to an } \\
\text { employee, which may be specified in an employment contract. It } \\
\text { is contrasted with piece wages, where each job, hour or other unit } \\
\text { is paid separately, rather than on a periodic basis. }\end{array}$ \\
\hline Compensation & $\begin{array}{c}\text { Compensation is something similar with pay or salary, typically a } \\
\text { monetary payment for services rendered, as in an employment. } \\
\text { Some benefits may be concluded. }\end{array}$ \\
\hline Total Compensation & $\begin{array}{c}\text { Total compensation includes pay, benefits, flexible schedules, } \\
\text { education assistance, training courses, and workplace } \\
\text { opportunities to help you get the most out of your career and } \\
\text { personal life. }\end{array}$ \\
\hline Total Reward & $\begin{array}{l}\text { Total reward covers all the elements that employees value in } \\
\text { working for their employer. It emphasizes the integrity of } \\
\text { remuneration and is put forward in contrast to total compensation. } \\
\text { Although at most times it is thought as the same as total } \\
\text { compensation, total reward remains the most new word in the } \\
\text { category of remuneration or reward. }\end{array}$ \\
\hline
\end{tabular}

Table 2. A Four-component Module (Patricia \& Jay, 2003)

\begin{tabular}{|c|c|}
\hline \multicolumn{2}{|c|}{ TOTAL REWARD COMPONENTS } \\
\hline Individual Growth & Compelling Future \\
\hline Total Pay & Positive Workplace \\
\hline
\end{tabular}




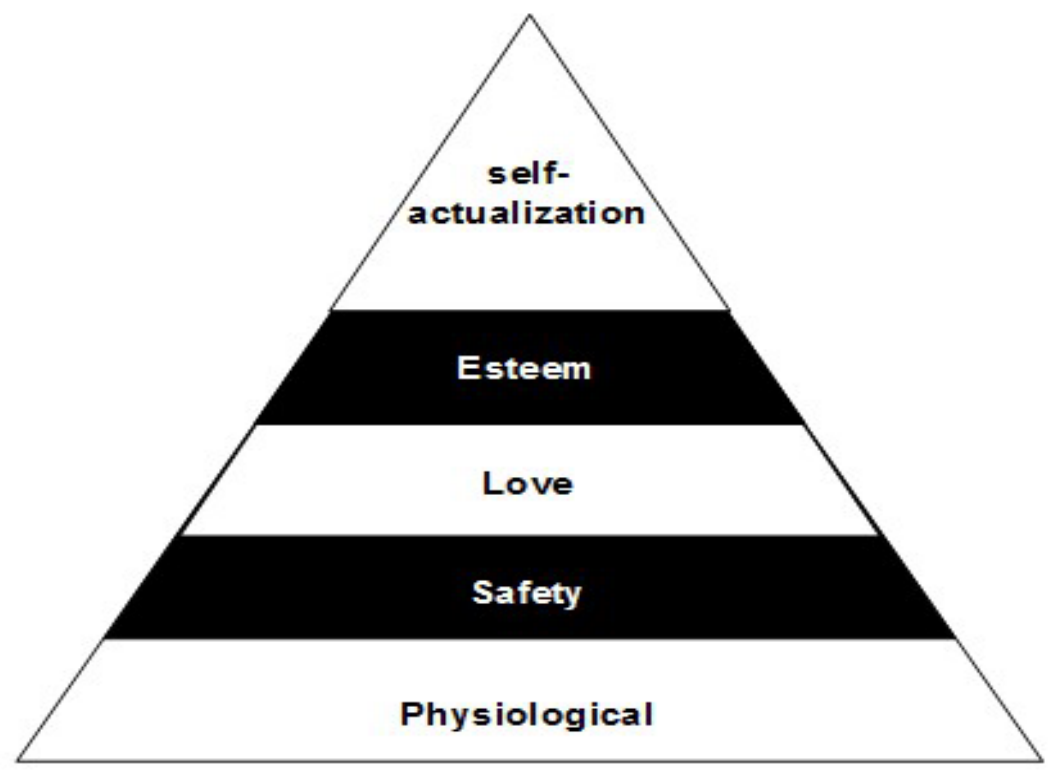

Figure 1. Maslow's Need Hierarchy

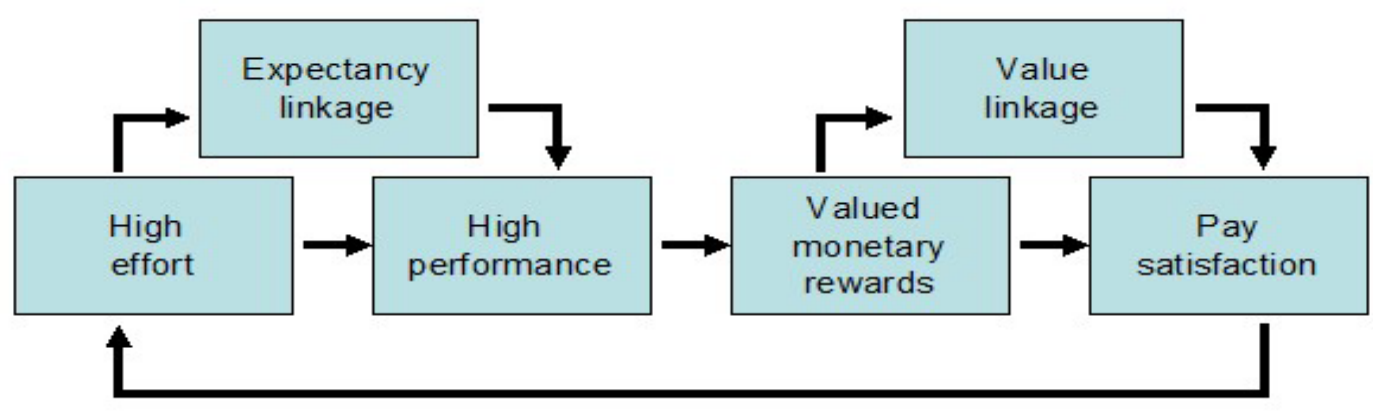

Figure 2. Pay-for-Performance and Expectancy Theory

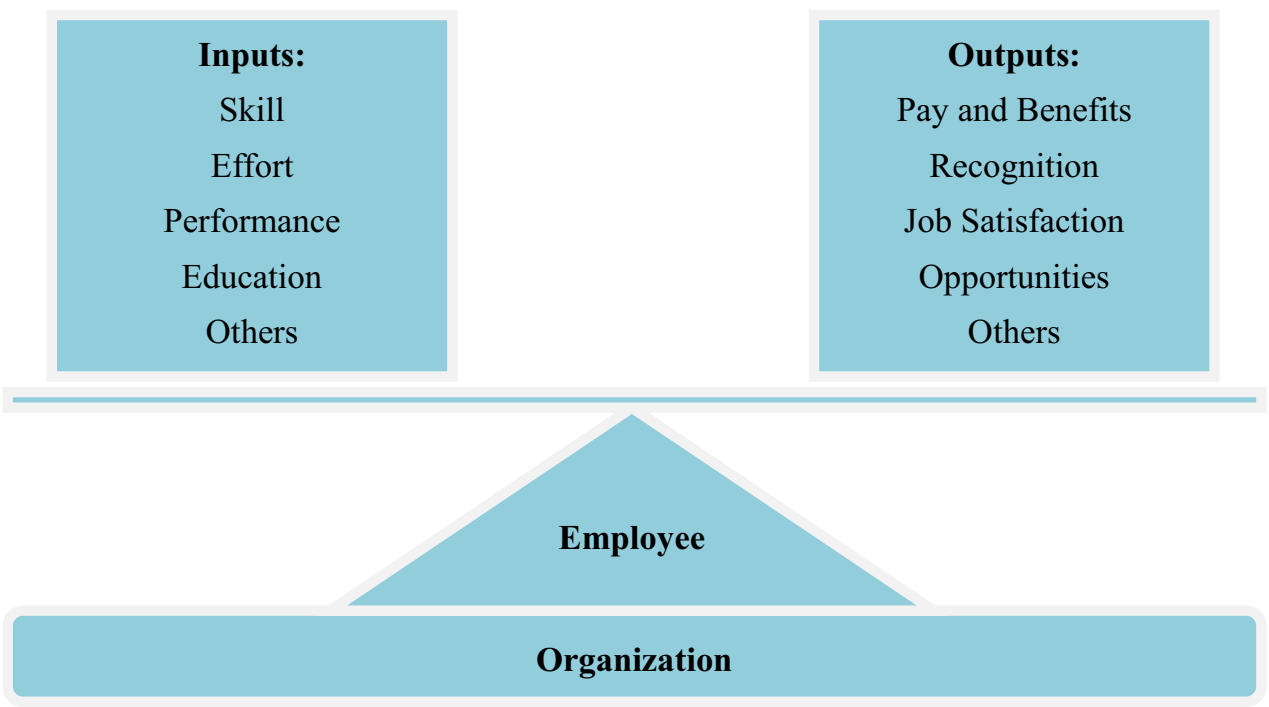

Figure 3. The equity theory of motivation assumes a balance of employee inputs and outputs as compared to others 